\title{
Correction to: Study and Analysis of Parameters Affecting Tubular Daylighting Device
}

\author{
Devendra Singh Bisht, Harry Garg, R. R. Shravana Kumar \\ and Vinod Karar
}

\section{Correction to:}

Chapter 9 in: V. K. Jain et al. (eds.),

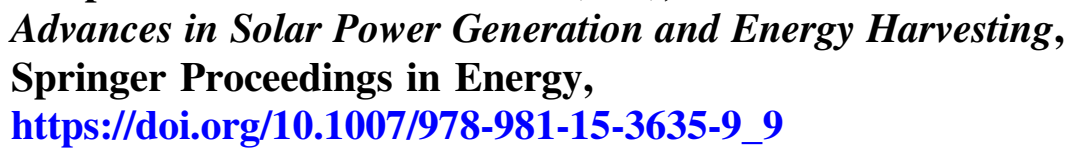

The original version of the book was inadvertently published with an incorrect affiliation of the authors. The affiliation (CSIR-Central Scientific Instruments Organisation, Sector 30C, Chandigarh 160030, India) of the authors in chapter 9 has been amended. The chapter and book have been updated with the changes. 